\title{
Socio-Demographic Factors and Their Correlation with the Severity of Major Depressive Disorder: A Population Based Study
}

\author{
Md. Rabiul Islam ${ }^{1 *}$, Rubyeat Adnan² \\ ${ }^{1}$ Department of Clinical Pharmacy and Pharmacology, Faculty of Pharmacy, University of Dhaka, Dhaka, Bangladesh \\ ${ }^{2}$ Department of Public Health, North South University, Dhaka, Bangladesh \\ Email: *robi.ayaan@gmail.com
}

How to cite this paper: Islam, Md.R. and Adnan, R. (2017) Socio-Demographic Factors and Their Correlation with the Severity of Major Depressive Disorder: A Population Based Study. World Journal of Neuroscience, 7, 193-202.

https://doi.org/10.4236/wjns.2017.72014

Received: February 2, 2017

Accepted: March 6, 2017

Published: March 9, 2017

Copyright $\odot 2017$ by authors and Scientific Research Publishing Inc. This work is licensed under the Creative Commons Attribution International License (CC BY 4.0). http://creativecommons.org/licenses/by/4.0/

\section{Open Access}

\begin{abstract}
Objective: Genetic and neurobiological factors are considered to be the major causes of major depressive disorder (MDD). However, over last few years study results revealed that socio-demographic factors contribute a significant role in abnormal functional activity and recognized as major causative factors to the pathogenesis and severity of MDD. The aim of this study was to assess the socio-demographic characteristics of Bangladeshi MDD patients and to discover their role on the severity of disease. Material and Methods: A retrospective review of the case notes of psychiatry outpatients at Bangabandhu Sheikh Mujib Medical University (BSMMU) was carried out between Sep-Nov 2016. A total of 234 MDD patients (aged 18 to 60 years) were randomly recruited. Relevant information was obtained by collection of prescription details from the patients or their relatives by face to face interview. Results: Mean age and body mass index (BMI) were found 34.734 years (SEM \pm 0.842 ) and $22.014 \mathrm{~kg} / \mathrm{m}^{2}$ respectively. Among all respondents, 56\% (133) were male and $44 \%$ (106) were female where mean income was 26.84 KBDT (Kilo Bangladeshi Taka) (SEM \pm 0.749 ). Roughly $46 \%$ (111) patients were found to be below secondary level of education. Married people (56\%) had a tendency to develop depression compare to unmarried people (36\%). Urban residents (64\%) are more prone to suffer from depression than rural residents (36\%). There was mild depression in $28 \%$ (68), moderate in $37 \%$ (157), and severe in $14 \%$ (34) patients. Correlation analysis shows that age, sex, marital status, education, family income, and area of residence (p-values 0.004, 0.001, 0.000, $0.011,0.000$ and 0.000 , respectively) are associated with the severity of disease. Moreover, among all significant correlations age, marital status and area of residence were positively correlated with the severity of $\operatorname{MDD}(r=0.184, r=$ 0.238 and $r=0.256$ ) while sex, education and family income were negatively correlated with the severity of depression $(r=-0.207, r=-0.164$ and $r=$
\end{abstract}


-0.722). Conclusion: Current study shows that age, gender, marital status, education, family income, and area of residence are associated with the severity of depression. Age, marital status and residence of MDD patients are positively correlated with the severity of disease while gender, education and family income are negatively correlated with the severity of depression. It is predicted that this study will be helpful for the management and assortment of MDD patients with more accuracy based on their socio-demographic features.

\section{Keywords}

Socio-Demographic Factors, Correlation, Severity, Major Depressive Disorder, Bangladesh

\section{Introduction}

Major depressive disorder (MDD) is considered as a persistent feeling of hopelessness or a lack of interest in external drives which is accompanied by low selfesteem and loss of pleasure or interest in daily events that unfavorably disturbs a person's family, effort and personal life [1]. Medical journal Neuron mentioned that she reedited as a fundamental cause of depression with almost 3-fold increased risk in the first-degree relatives of persons with MDD compare to general population [2]. This means that the single biggest determining factor for depression is family tree, but there also is a significant physiological and anatomical basis [3]. However, over the past few years, socio-demographic characteristics involved in abnormal functional activity have been recognized as major causative factors to the pathogenesis and severity of MDD [4]. Based on previous studies, risk factors for depressive illness in the elderly can be grouped into psychosocial, biological, personality characteristics, medication and socio-demographic factors [5]. Psychosocial factors include stressful life events e.g. bereavement, financial failures, loneliness etc. [6]. Biological factors include: female gender, folate and vitamin $\mathrm{B}_{12}$ deficiency, "vascular depression" where stroke is implicated and chronic or severe physical pain [7]. Personality traits include low self-esteem, extreme dependency and pessimism [8]. Medication includes anxiolytics, tranquilizers, anti-inflammatory, anti-infective agents, beta and calcium channel blockers, hormonal agents, cardio tonic drugs and alcohol [9]. Finally, socio-demographic factors related with depression are low socio-economic status, poor educational background, and widowhood [10].

Age, gender, education, income, and marital status have been identified as important contributing factors for the variability and prevalence of depression. Many studies established that prevalence rate of depression varying from $2.8 \%$ to $10.3 \%$ based on socio-demographic factors e.g. age and gender [11] [12] [13]. Patten et al. found significant correlations among age, gender, and marital status of single women reporting lower rates of depression [14]. Some previous research also found that age is the main demographic feature that contributes much in the prevalence of depression [13]. Women's prevalence of depression 
also differs by age, over 65 years of age 3.1\% women suffer from depression and $9.6 \%$ for the age group 12 to 24 [13]. Occurrence of depressive episode has also been significantly depends on gender [15]. Usually risk factors for having depression is 2 - 3 fold higher with females compared to males [11] [12] [13] [16]. In addition to gender, marital status has also been identified as major contributing factors for the variance in the prevalence of depression. In Australia, separated and divorced people suffer more from anxiety disorders (18\%) and affective disorders (12\%) [17]. In Canada, prevalence of depression was found $15.4 \%$ among single mothers compared to $6.8 \%$ in married mothers [18]. Many studies endorsed a strong opposite relationship between mental disorder and socioeconomic status [15] [19] [20] [21].

In Bangladesh, 4.6\% population have any form of depression and among all psychiatric patients, $28.7 \%$ suffer from major depressive disorder. Both females and singles have a tendency to suffer from depression more than others [22]. Many studies showed that the chance of having major depression is double in women than men but the reason is unknown and which factors actually responsible for this are also unknown [23]. People usually experience their first episode of depression during the fourth decade of life and there may be a second smaller peak at the age between 50 to 60 years. Chance of having depressive episodes is associated with some states of diseases such as Parkinson's disease, stroke, or multiple sclerosis [24].

\section{Material and Methods}

A retrospective review of the case notes of outpatients was carried out from September to November 2016. A total of 238MDD patients, age ranging from 18 to 60 years, were randomly recruited from the outpatient Department of Psychiatry, Bangabandhu Sheikh Mujib Medical University (BSMMU) Hospital, Bangladesh. Patients under the age of 18 , above the age of 60 or those having a severe general medical condition were not included in the study. A specialist psychiatrist conducted the diagnosis and interview of the patients based on Diagnostic and Statistical Manual of Mental Disorders, 5th edition (DSM-V, 2013) [25]. Where physician generally notice few mental changes of patients to be diagnosed as MDD e.g. depressed mood or a loss of interest or pleasure in daily activities for more than two weeks, mood represents a change from the person's baseline and impaired social, occupational and educational activities. Along with the above changes at least 5 specific symptoms (out of 9) will also be present nearly every day in MDD patients. Severity of depression is categorized as mild, moderate and severe. Mild depression, where 5 - 6 specific symptoms were present and functional impairment was also mild. Moderate depression, where 7 - 8 specific symptoms were present and moderate functional impairment was also present. Severe depression is termed as where most of symptoms were present with severe functional impairment, recent suicide attempt, or has specific suicide plan or clear intent. The data were taken by collection of prescription 
details from the patients or their relatives by face to face interview with them. The study subjects were informed about the objective of the study and a written consent was taken from each of them. Each of the subjects filled up a questionnaire form which contains personal information, socio-economic data, history of illness, family history and other demographic and medical information. The forms of the patients who had no formal education were filled out with the help of their primary care givers. Study protocol and volunteer consent form was approved by the ethical review committee of Department of Psychiatry, BSMMU. Statistical analysis was performed using the statistical software package SPSS, version 23.0 (SPSS Inc., Chicago, IL). Descriptive data has been given as frequencies and percentages.

\section{Results}

The socio-demographic characteristics of the respondents are shown in Table 1. Approximately 59\% (141) patients were found within an age range of $25-44$ years. Average body mass index (BMI) was found $22.014 \mathrm{~kg} / \mathrm{m}^{2}$ where $74 \%$ (178) patients were in normal BMI range. Among all respondents, 56\% (133) were male and 44\% (106) were female. Roughly $46 \%$ (111) patients were found to be below secondary level of education, whereas $17 \%, 19 \%$ and $18 \%$ respondents had education equivalent to secondary, higher secondary and graduation or higher respectively. Mean values of socio-demographic factors of study population were expressed in Table 2 where patients had a mean age of 34.734 years (SEM \pm 0.842). Among all respondents $33 \%$ were jobless as well as having family income below $10 \mathrm{KBDT}$ (Kilo Bangladeshi Taka) and their mean income was 26.84 KBDT (SEM \pm 0.749 ). As per the finding of current study, married people (56\%) had a tendency to develop depression than unmarried people (36\%). Twenty percent of depressed person had their family history of any psychiatric disorder. Urban residents (64\%) are more prone to suffer from depression than rural residents (36\%). In Bangladesh, cigarette smoking habit among females is rare but we found 35\% (84) MDD patients as smoker. There was mild depression in 28\% (68), moderate in $37 \%$ (157), and severe in 14\% (34) patients (Figure 1).

Correlation analysis between socio-demographic factors and severity of MDD was given in Table 3 . Our current study shows that there was statistically significant correlation between different socio-demographic parameters and severity of depression. Results from correlation analysis shows that at 95\% confidence interval age, sex, marital status, level of education, monthly income, and area of residence (p-values $0.004,0.001,0.000,0.011,0.000$ and 0.000 , respectively) are associated with disease severity while BMI ( $p$-value 0.175$)$ and smoking habit (p-value 0.960$)$ were not significantly correlated with severity of depression. Moreover, among all significant correlations age, marital status and area of residence were positively correlated with the severity of $\operatorname{MDD}(\mathrm{r}=0.184, \mathrm{r}=0.238$ and $r=0.256$ ) while sex, education and family income were negatively correlated with the severity of depression $(r=-0.207, r=-0.164$ and $r=-0.722)$. 
Table 1. Socio-demographic status of major depressive disorder patients described as frequencies and percentages.

\begin{tabular}{|c|c|c|c|}
\hline \multirow{2}{*}{\multicolumn{2}{|c|}{ Parameter }} & \multicolumn{2}{|c|}{ Respondents $(\mathrm{n}=239)$} \\
\hline & & \multirow[t]{2}{*}{$\mathrm{n}$} & \multirow[t]{2}{*}{$\%$} \\
\hline Age in years & & & \\
\hline & $18-24$ & 38 & 16 \\
\hline & $25-34$ & 72 & 30 \\
\hline & $35-44$ & 69 & 29 \\
\hline & $45-60$ & 60 & 25 \\
\hline \multicolumn{4}{|l|}{ BMI $\left(\mathrm{kg} / \mathrm{m}^{2}\right)$} \\
\hline & Below 18.5 (CED) & 34 & 14 \\
\hline & 18.5 - 25 (normal) & 178 & 74 \\
\hline & Above 25 (obese) & 27 & 11 \\
\hline \multicolumn{4}{|l|}{ Sex } \\
\hline & Male & 133 & 56 \\
\hline & Female & 106 & 44 \\
\hline \multicolumn{4}{|l|}{ Education } \\
\hline & Illiterate & 53 & 22 \\
\hline & Can read only & 58 & 24 \\
\hline & Secondary & 41 & 17 \\
\hline & Higher secondary & 45 & 19 \\
\hline & Graduate and above & 42 & 18 \\
\hline \multicolumn{4}{|l|}{ Occupation } \\
\hline & Service & 44 & 18 \\
\hline & Business & 36 & 15 \\
\hline & Jobless & 78 & 33 \\
\hline & Student and others & 81 & 34 \\
\hline \multicolumn{4}{|l|}{ Monthly income in KBDT } \\
\hline & Below 10 & 78 & 33 \\
\hline & $10-25$ & 104 & 44 \\
\hline & $26-40$ & 45 & 19 \\
\hline & Above 40 & 12 & 5 \\
\hline \multicolumn{4}{|l|}{ Marital status } \\
\hline & Unmarried & 87 & 36 \\
\hline & Married & 134 & 56 \\
\hline & Divorced/widowhood & 18 & 8 \\
\hline \multicolumn{4}{|l|}{ Residence } \\
\hline & Urban & 152 & 64 \\
\hline & Rural & 87 & 36 \\
\hline \multicolumn{4}{|l|}{ Family history of psychiatric disorder } \\
\hline & Yes & 191 & 80 \\
\hline & No & 48 & 20 \\
\hline \multicolumn{4}{|l|}{ Smoking history } \\
\hline & Smoker & 84 & 35 \\
\hline & Non-smoker & 155 & 65 \\
\hline
\end{tabular}




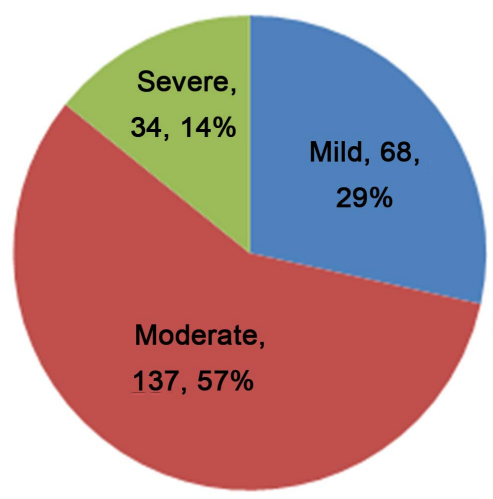

Figure 1. Distribution of MDD patients based on the severity.

Table 2. Socio-demographic factors of study population (mean values with standard error mean).

\begin{tabular}{cc}
\hline Parameter & Respondents $(\mathrm{n}=239)$ \\
\cline { 2 - 2 } Age (years) & Values (Mean \pm SEM) \\
BMI $\left(\mathrm{kg} / \mathrm{m}^{2}\right)$ & $34.734 \pm 0.842$ \\
Family income $\left(\mathrm{KBDT}^{*}\right)$ & $22.014 \pm 0.537$ \\
\hline
\end{tabular}

*Kilo Bangladeshi Taka.

Table 3. Correlation between socio-demographic factors and severity of major depressive disorder.

\begin{tabular}{ccc} 
Parameter & \multicolumn{2}{c}{ Respondents $(\mathrm{n}=239)$} \\
\cline { 2 - 3 } Age & $\mathrm{r}$ & $p$ \\
Sex & $0.184^{*}$ & 0.004 \\
BMI & $-0.207^{*}$ & 0.001 \\
Education & -0.088 & 0.175 \\
Family income & $-0.164^{*}$ & 0.011 \\
Marital status & $-0.722^{*}$ & 0.000 \\
Smoking habit & $0.238^{*}$ & 0.000 \\
Area of residence & -0.003 & 0.960 \\
\hline
\end{tabular}

$\mathrm{r}=$ Correlation co-efficient; $p=$ Significance; Negative values specify opposite correlation. ${ }^{*}$ Correlation is significant at 0.05 level (two-tailed).

\section{Discussion}

This study was conducted to explore the socio-demographic status of MDD patients attending at outpatient department of a tertiary care teaching hospital in Bangladesh. Also find out the correlation between socio-demographic status and severity of the disorder. Our study findings were comparable with similar previous studies in some other countries. As per current study approximately 59\% patients were found within an age range of $25-44$ years where $74 \%$ patients 
were in normal BMI range. Similar result was stated in another study where they found people usually experience depressive episode during their forth decade of life [24] and more than 50\% patients had normal body weight [26]. We found $56 \%$ male and $44 \%$ female patients as per this study which is not similar with some previous study results where reported that chance of having major depression is twice in women than men [23]. Actual fact behind this inconsistent result is our social behavior to psychiatric patients because they are neglected especially for female patients compare to any patients suffering from other diseases. About $46 \%$ patients were found below secondary level of education, 17\%, 19\% and $18 \%$ were corresponding to secondary, higher secondary and graduation or higher, respectively. The results are comparable with previous studies reporting associations between individuals with educational status and depression, e.g. significantly more incidents of MDD occur among those with lower educational background [27]. Among all respondents 33\% were jobless as well as having family income below $10 \mathrm{KBDT}$ (Kilo Bangladeshi Taka) which is consistent with study results in China that is lower socioeconomic status is linked with augmented rates of depression [27]. We found married people had a tendency to develop depression than unmarried people. This result is consistent with other previous studies where married person had increased risk to fall in depression in both genders [28]. As per our study result, people with family history of any psychiatric disorders had increased risk to develop depression which is supported by some other study findings [29]. Urban residents are more prone to suffer from depression than rural residents which also similar with other findings [30].

Results from correlation analysis shows that age, sex, marital status, level of education, monthly income, and area of residence were associated with the severity of disease while BMI and smoking habit were not significantly correlated with severity of depression. Furthermore, age, marital status and area of residence were positively correlated with the severity of MDD while sex, education and family income were negatively correlated with the severity of depression. A study among Chinese people supported these findings where age, study year, satisfaction with major, family income situation, parental relationship and mother's education were significantly associated with depression [31].

The limitation of our current study was we did not explore any biological parameters in MDD patients although alterations of some of these elements may play an important role for developing depression. Therefore, further study may be required to determine whether social conditions influence on the severity of depression or other biological markers influence depression more. Another drawback of our present study was we took samples from single center. So, if we want to produce more accurate conclusion for our present study, we need to carry out this study over large number of samples from different regional part of Bangladesh. In spite of these limitations, we hope our study will play an important role to understand the association between socio-demographic status and severity of depression. 


\section{Conclusion}

This study shows that age, sex, marital status, level of education, monthly income, and area of residence were associated with the severity of depression. Age, marital status and residence of MDD patients are positively correlated with the severity of disease while sex, education and family income are negatively correlated with the severity of depression. This strong association between depression and socio-demographic status will play an important role to understand and treat the disease. It is anticipated that this study will be helpful for not only management of MDD but also assortment of patients with more precision based on their socio-demographic features.

\section{Acknowledgements}

The authors are thankful to all the staffs of outpatient department of psychiatry, BSMMU, for their precious time, technical and administrative support for the collection of data throughout the study period. The authors are also thankful to all the patients and their caregivers for their cooperation to this study.

\section{Ethical Standards}

Ethical approval was obtained from the ethical review committee at the department of psychiatry, BSMMU. All data were collected from the department of psychiatry, BSMMU, Dhaka, Bangladesh. All the participants were sufficiently educated about the purpose and benefits of the study. A structured evaluator managed questionnaire was used to collect data. Each subject gave written informed consent to participate in the study and agreed that unidentified data would be presented at academic purpose or can be published in journal articles.

\section{Conflict of Interest}

The authors declare that there is no conflict of interests regarding the publication of this article.

\section{References}

[1] Wakefield, J.C., Schmitz, M.F., First, M.B. and Horwitz, A.V. (2007) Extending the Bereavement Exclusion for Major Depression to Other Losses: Evidence from the National Comorbidity Survey. Archives of General Psychiatry, 64, 433-440. https://doi.org/10.1001/archpsyc.64.4.433

[2] Flint, J. and Kendler, K.S. (2014) The Genetics of Major Depression. Neuron, 81, 484-503. https://doi.org/10.1016/j.neuron.2014.01.027

[3] Slavich, G.M. and Irwin, M.R. (2014) From Stress to Inflammation and Major Depressive Disorder: A Social Signal Transduction Theory of Depression. Psychological Bulletin, 140, 774-815. https://doi.org/10.1037/a0035302

[4] Amadi, K.U., Uwakwe, R., Ndukuba, A.C., Odinka, P.C., Igwe, M.N., Obayi, N.K. and Ezeme, M.S. (2016) Relationship between Religiosity, Religious Coping and Socio-Demographic Variables among Out-Patients with Depression or Diabetes Mellitus in Enugu, Nigeria. African Health Sciences, 16, 497-506.

https://doi.org/10.4314/ahs.v16i2.18 
[5] Sözeri-Varma, G. (2012) Depression in the Elderly: Clinical Features and Risk Factors. Aging and Disease, 3, 465-471. https://www.ncbi.nlm.nih.gov/pmc/articles/PMC3522513/

[6] Bruce, M.L. (2001) Psychological Risk Factor for Depressive Disorder in Late Life. Biological Psychiatry, 52, 175-184. https://doi.org/10.1016/S0006-3223(02)01410-5

[7] Tiemeier, H. (2003) Biological Risk Factors for Late Life Depression. European Journal of Epidemiology, 18, 745-750.

https://www.ncbi.nlm.nih.gov/pubmed/12974548 https://doi.org/10.1023/A:1025388203548

[8] Swinkels, W.A.M., Van Emde Boas, W., Kuyk, J., Van Dyck, R. and Spinhoven, P. (2006) Interictal Depression, Anxiety, Personality Traits, and Psychological Dissociation in Patients with Temporal Lobe Epilepsy (TLE) and Extra-TLE. Epilepsia, 47, 2092-2103. https://doi.org/10.1111/j.1528-1167.2006.00808.x

[9] Pratt. L.A., Ford, D.E., Crum, R.M., Armenian, H.K., Gallo, J.J. and Eaton, W.W. (1996) Depression, Psychotropic Medication, and Risk of Myocardial Infarction. Prospective Data from the Baltimore ECA Follow-Up, Circulation, 94, 3123-3129. https://doi.org/10.1161/01.CIR.94.12.3123

[10] Mills, T.N. and Henretta, J.C. (2001) Racial, Ethnic and Sociodemographic Differences in the Level of Psychosocial Difference among Older Americans. Research on Ageing, 23, 131-152. https://doi.org/10.1177/0164027501232001

[11] Offord, D.R., Boyle, M.H., Campbell, D., Goering, P., Lin, E., Wong, M. and Racine, Y.A. (1996) One-Year Prevalence of Psychiatric Disorder in Ontarians 15 to 64 Years of age. Canadian Journal of Psychiatry, 41, 559-563.

https://www.ncbi.nlm.nih.gov/pubmed/8946078

[12] Kessler, R.C., McGonagle, K.A., Zhao, S., Nelson, C.B., Hughes, M., Eshleman, S., Wittchen, H. and Kendler, K.S. (1994) Lifetime and 12-Month Prevalence of DSMIII-R Psychiatric Disorders in the United States Results From the National Comorbidity Survey. Archives of General Psychiatry, 51, 8-19. https://doi.org/10.1001/archpsyc.1994.03950010008002

[13] Patten, S.B. (2000) Incidence of Major Depression in Canada. Canadian Medical Association Journal, 163, 714-715. https://www.ncbi.nlm.nih.gov/pmc/articles/PMC80167/

[14] Patten, S.B., Wang, J.L, Williams, J.V, Currie, S., Beck, C.A., Maxwell, C.J. and El-Guebaly, N. (2006) Descriptive Epidemiology of Major Depression in Canada. Canadian Journal of Psychiatry, 51, 84-90.

https://www.ncbi.nlm.nih.gov/pubmed/16989107 https://doi.org/10.1177/070674370605100204

[15] Wade, T.J., Cairney, J. and Pevalin, D.J. (2002) Emergence of Gender Differences in Depression during Adolescence: National Panel Results from Three Countries. Journal of the American Academy of Child and Adolescent Psychiatry, 41, 190-198. https://doi.org/10.1097/00004583-200202000-00013

[16] Kornstein, S.G., Schatzberg, A.F., Thase, M.E., Yonkers, K.A., McCullough, J.P., Keitner, G.I., Gelenberg, A.J., Ryan, C.E., Hess, A.L., Harrison, W., et al. (2000) Gender Differences in Chronic Major and Double Depression. Journal of Affective Disorders, 60, 1-11. https://doi.org/10.1016/S0165-0327(99)00158-5

[17] Australian Bureau of Statistics (2006). http://www.abs.gov.au/Ausstats/abs@.nsf/Lookup/670D4F8706B05404CA2568A900 $\underline{136280}$

[18] Cairney, J., Thorpe, C., Rietschlin, J. and Avison, W.R. (1999) 12-Month Prevalence of Depression among Single and Married Mothers in the 1994 National Population 
Health Survey. Canadian Journal of Public Health, 90, 320-324. https://www.ncbi.nlm.nih.gov/pubmed/10570576

[19] Eaton, W.W., Muntaner, C., Bovasso, G. and Smith, C. (2001) Socioeconomic Status and Depressive Syndrome: The Role of Inter- and Intra-Generational Mobility, Government Assistance, and Work Environment. Journal of Health and Social Behavior, 42, 277-294. https://www.ncbi.nlm.nih.gov/pmc/articles/PMC2802838/ https://doi.org/10.2307/3090215

[20] Lennon, M.C., Blome, J. and English, K. (2002) Depression among Women on Welfare: A Review of the Literature. Journal of the American Medical Women's Association, 57, 27-31, 40. https://www.ncbi.nlm.nih.gov/pubmed/11905486

[21] Lorant, V., Deliège, D., Eaton, W., Robert, A., Philippot, P. and Ansseau, M. (2003) Socioeconomic Inequalities in Depression: A Meta-Analysis. American Journal of Epidemiology, 157, 98-112. https://doi.org/10.1093/aje/kwf182

[22] Firoz, A.H.M., Karim, M.E., Alam, M.F., Rahman, A.H.M., Zaman, M.N. and Chandra, V. (2006) Community Based Multicentric Service Oriented Research on Mental Illness with Focus on Prevalence, Medical Care, Awareness and Attitude towards Mental Illness in Bangladesh. Bangladesh Journal of Psychiatry, 20, 9-32.

[23] Kuehner, C. (2003) Gender Differences in Unipolar Depression: An Update of Epidemiological Findings and Possible Explanations. Acta Psychiatrica Scandinavica, 108, 163-174. https://doi.org/10.1034/j.1600-0447.2003.00204.x

[24] Rickards, H. (2005) Depression in Neurological Disorders: Parkinson's Disease, Multiple Sclerosis, and Stroke. Journal of Neurology, Neurosurgery, and Psychiatry, 76, 48-52. https://doi.org/10.1136/jnnp.2004.060426

[25] DSM-V (2013) Diagnostic and Statistical Manual for Mental Disorders. 5th Edition, American Psychiatric Association.

[26] De Wit, L.M., van Straten, A., van Herten, M., Penninx, B.W. and Cuijpers, P. (2009) Depression and Body Mass Index, a U-Shaped Association. BMC Public Health, 9, 14. https://doi.org/10.1186/1471-2458-9-14

[27] Shi, J., Zhang, Y., Liu, F., Li, Y., Wang, J., Flint, J., et al. (2014) Associations of Educational Attainment, Occupation, Social Class and Major Depressive Disorder among Han Chinese Women. PLoS ONE, 9, e86674. https://doi.org/10.1371/journal.pone.0086674

[28] Scott, K.M., Wells, J.E., Angermeyer, M., Brugha, T.S., Bromet, E., et al. (2010) Gender and the Relationship between Marital Status and First Onset of Mood, Anxiety and Substance Use Disorders. Psychological Medicine, 40, 1495-1505. https://doi.org/10.1017/S0033291709991942

[29] Rasic, D., Hajek, T., Alda, M. and Uher, R. (2014) Risk of Mental Illness in Offspring of Parents With Schizophrenia, Bipolar Disorder, and Major Depressive Disorder: A Meta-Analysis of Family High-Risk Studies. Schizophrenia Bulletin, 40, 28-38. https://doi.org/10.1093/schbul/sbt114

[30] Gu, L., Xie, J., Long, J., Chen, Q., Chen, Q., Pan, R. and Su, L. (2013) Epidemiology of Major Depressive Disorder in Mainland China: A Systematic Review. PLoS ONE, 8, e65356. https://doi.org/10.1371/journal.pone.0065356

[31] Chen, L., Wang, L., Qiu, X.H., Yang, X.X., Qiao, Z.X., Yang, Y.J. and Liang, Y. (2013) Depression among Chinese University Students: Prevalence and Socio-Demographic Correlates. PLoS ONE, 8, e58379.

https://doi.org/10.1371/journal.pone.0058379 
Submit or recommend next manuscript to SCIRP and we will provide best service for you:

Accepting pre-submission inquiries through Email, Facebook, LinkedIn, Twitter, etc. A wide selection of journals (inclusive of 9 subjects, more than 200 journals)

Providing 24-hour high-quality service

User-friendly online submission system

Fair and swift peer-review system

Efficient typesetting and proofreading procedure

Display of the result of downloads and visits, as well as the number of cited articles Maximum dissemination of your research work

Submit your manuscript at: http://papersubmission.scirp.org/

Or contact wins@scirp.org 